\title{
A importância da educação física como forma inclusiva numa perspectiva docente*
}

\author{
Education importance of physics as \\ inclusive form in perspective faculty
}

Fabiane Matos Lara ${ }^{1}$ Celeida Belchior Garcia Cintra Pinto ${ }^{2}$
Recebido em: 26/09/2016. Aprovado em: 23/11/2016.

1 Licenciada em Educação Física/UNICEUB. E-mail: fabianelara@hotmail.com.

2 Pedagoga, formada pela FAFI/Santo Tomas de Aquino, MG; Mestrado em Educação pela UCB/DF. Professora do curso de Educação Física/UNICEUB. E-mail: celeida.pinto@uniceub.br.

\section{Resumo}

O presente artigo teve como objetivo de estudo investigar de que forma a Educação Física contribui para o desenvolvimento inclusivo dos alunos que apresentam necessidades educacionais especiais, juntamente a dez professores de Educação Física de uma escola pública do Distrito Federal. Utilizou-se como recurso um questionário com perguntas fechadas e abertas. Os dados coletados foram analisados por meio do programa Word e Excel 2010. Verificou-se que 50\% dos professores consideram a inclusão uma forma gradativa respeitando a capacidade, especificidades e o processo de aprendizagem e $20 \%$ apontam como dificuldade a falta de material, monitores e falta de espaço físico. Concluiuse que a prática de atividades físicas é considerada fundamental nos processos de inclusão de alunos que apresentam necessidades especiais, em turmas regulares, contribuindo para o desenvolvimento cognitivo, afetivo e motor, ressaltando a relevância dos professores de Educação Física nesse processo.

Palavras-chave: Inclusão. Educação Física. Contexto escolar. Visão dos docentes.

\begin{abstract}
This research aimed to study investigating how the physical education contributes to the comprehensive development of students with special educational needs, with ten physical education teachers of a public school in the Federal District. It was used as a resource a questionnaire with closed and open questions. Data were analyzed using the program Word and Excel 2010. It was found that $50 \%$ of teachers consider including a gradual manner respecting the capacity characteristics and the learning process and $20 \%$ point out how difficult the lack of material, monitors and lack of physical space. It was concluded that physical activity is considered fundamental in the inclusion process of students with special needs in regular classes, contributing to the cognitive, affective and motor, emphasizing the importance of physical education teachers in the process. Keywords: Inclusion. Physical education. School context. Vision of teachers.
\end{abstract}




\section{Introdução}

A inclusão começou a ser um processo perceptível a partir de 1980 nos países desenvolvidos. Em escala nacional, somente a partir da sétima Constituição da República (1988) que o número de pesquisas e estudos nessa área começou a ampliar-se (AGUIAR; DUARTE, 2005).

Os autores ressaltam que, no campo da educação escolar, a busca por uma educação inclusiva e pelo estudo nessa área, de forma sistematizada, está assegurada pela Lei de Diretrizes e Bases da Educação Nacional de 1996.

A LDB n ${ }^{\circ}$ 9394/96, no capítulo V, Art. 58, trata da Educação Especial como sendo a modalidade de educação escolar ofertada na rede regular de ensino, para alunos que apresentam necessidades educacionais especiais, com serviço de apoio especializado para atendê-los. $\mathrm{O}$ Art. $59^{\circ}$, inciso III, assegura professores especializados e capacitados para trabalhar a integração desses alunos nas classes comuns (BRASIL, 1996).

Os Parâmetros Curriculares Nacionais de Educação Física afirmam que a participação desses alunos nas aulas de Educação Física, quando orientada e estruturada adequadamente, pode trazer benefícios para eles, principalmente proporcionando integração, inserção social e desenvolvimento de suas capacidades afetivas (BRASIL, 1998).

A Declaração de Salamanca, uma resolução das Nações Unidas, resultado da Conferência Mundial de Educação Especial, de junho de 1994, é considerada umas das mais importantes diretrizes mundiais, definindo princípios, políticas e práticas em Educação Especial. Sua proposta, voltada para a criança com necessidades especiais, demanda que o governo proponha ações e assegure o recrutamento e treinamento de professores, tanto em formação quanto em serviço, qualificando-os para atender à educação especial e possibilitando a inclusão dessas crianças no ensino regular, em nível nacional (UNESCO, 1994).

O professor tem grande importância nos processos de inclusão, enfrentando os desafios vivenciados no ensino regular. É preciso que o professor promova programas com qualidade e segurança, que conheça algumas características fundamentais sobre cada deficiência e, sobretudo, consiga perceber as potencialidades diferenciadas presentes nas crianças, independentemente das deficiências que possam apresentar (GORGATTI, 2008). mações, sendo elas pequenas ou grandes e partem do ambiente físico ao psicológico. Essas relações devem partir de uma mentalidade consciente desse processo inclusivo, incluindo a ciência das pessoas com necessidades especiais, tendo como finalidade formar uma sociedade que esteja preparada a valorizar as diferenças individuais e compreendê-las (CIDADE; FREITAS, 2002).

Silva e Salgado (2005) afirmam que devem ser implantadas culturas de inclusão a partir de três ideias centrais. A primeira é o entendimento do que é cultura de inclusão; a segunda: refere-se ao fato de que a inclusão não se restringe àqueles com necessidades especiais e a terceira ressalta que o professor deve ter uma perspectiva humanista, buscando enxergar e entender como ocorrem as relações sociais naquele ambiente e como cada aluno se sente durante esse processo.

A inclusão é a capacidade de se ver no outro, de aceitação, de compartilhar experiências com vários tipos de pessoas. Existem diversos tipos de discriminações, mas a inclusão é uma só, pois, por meio de uma visão inclusiva, todas as pessoas são acolhidas, sem qualquer exceção. O intuito da inclusão é, portanto, trazer todos para a sociedade, a qual deverá adequar-se e se adaptar aos particulares de todos em todas as áreas sociais (SASSAKI, 1999).

Para Cardoso (2003), a inclusão na escolar regular é um dos grandes desafios do Século XXI. A falta de uma percepção mais humana social diante das deficiências ou das diferenças traz consigo uma visão taxativa a respeito das necessidades especiais. Toda inclusão, toda relação com o outro, parte de um momento de interação. A ruptura nesses parâmetros discriminatórios pode ser alcançada por interferência do professor. Educação Física Adaptada é uma área que está crescendo, no ambiente inclusivo, o professor deverá ser paciente, criativo e observador.

O professor é primordial nessa relação e nesse processo inclusivo, pois essa forma de educação propõe grandes desafios. O professor é o principal mediador nas relações entre os alunos, é por meio da intervenção crítica e social do professor que os alunos podem ter uma nova visão sobre as diferenças entre os outros e entre si. (MARTINS, 2005).

Cidade e Freitas (2002) defendem que a Educação física, de forma adaptada, surgiu, oficialmente, na formação dos professores em cursos de graduação, sendo estabelecida legalmente na Resolução número 03/87, do 
Conselho Federal de Educação. Nessa resolução foi prevista a atuação do professor de Educação Física com necessidades especais.

A educação física inclusiva deve ter como eixo o aluno, para que se desenvolvam competências e condições igualitárias, buscando, portanto, estratégias para dirimir a exclusão ou segregação. É por meio das atividades de educação física que os alunos podem ampliar esses contatos interpessoais, já que as atividades físicas propiciam o ensino de limites e superação, além de dar uma visão de competitividade e, também, a ter contatos físicos que são propostos pelas dinâmicas das práticas educativas que valorizem a diversidade e o respeito entre os alunos (AGUIAR; DUARTE, 2005)

Além dessa missão democrática, a escola vem com um aspecto primordial, inserir crianças em um processo socializador. O processo inclusivo das crianças que apresentam necessidades especiais, na escola e também na prática da educação física, é primordial às relações sociais. Há uma relação benéfica mútua entre o aluno que apresenta necessidades especiais e o aluno considerado "normal," em que o ensino inclusivo é a atividade que busca a inclusão de todas as pessoas, de forma imparcial quanto ao talento individual e às deficiências (sensorial, física ou cognitiva), independente de origem econômica ou sociocultural (CARVALHO, 1998; OLIVEIRA; POKER, 2002).

De acordo com Darido (2008), a educação física, como prática escolar, integra o aluno na cultura corporal, ajudando na formação cidadã, para que este possa reproduzir e até mesmo transformar essa cultura. Segundo o mesmo autor, a prática da educação física tem um papel de desenvolver aspectos individuais e coletivos, além de trabalhar o desenvolvimento motor, a aptidão física e o bem-estar social. No modelo educacional anterior, no qual havia a segregação entre os alunos especiais e os outros alunos, não havia uma preocupação por essa inserção social.

Para que essas adaptações influam em um caráter inclusivo, os professores e a estrutura escolar devem estar preparados para receber os alunos de acordo com suas características individuais e com seu tipo de deficiência. Desde a elaboração do programa de atividades para que se tenha um ambiente realmente inclusivo, o professor deve estudar o ambiente e os acontecimentos de acordo com o contexto dos indivíduos que compõem o grupo (ALMEIDA; DUARTE; SILVA, 2011).
Para Maciel (2000), o ajustamento entre o professor e o aluno só acontece quando há uma relação isenta de preconceito, cabendo ao professor intermediar e favorecer o desenvolvimento dos alunos com necessidades especiais. Educar e estabelecer essa relação são tarefas árduas, mas contar com esforços de ambas as partes é algo que pode se tornar possível.

Dessa forma, de acordo Stainback e Stainback (1999), o professor deverá se adequar a essa nova proposta pedagógica, sendo necessário considerar a diversidade social, cultural, física ou qualquer outra. O professor pode explorar variáveis dentro da prática da educação física para fomentar processos inclusivos, além de viabilizar uma melhor aceitação do outro e de si mesmo. A educação física mediada por um professor inovador pode ser uma forma criativa de desvencilhar preconceitos e aumentar formas de efetiva inclusão.

Assim, o objetivo da presente pesquisa foi verificar como os alunos que apresentam necessidades especiais podem ser integrados ao ambiente inclusivo por meio da Educação Física, observando as dificuldades encontradas pelos professores nessa mediação, de forma inclusiva.

\section{Materiais e Métodos}

Este estudo trata de uma pesquisa transversal de coleta única, de análise exploratória. A amostra foi composta por dez professores de Educação Física, de ambos os sexos, de uma escola pública de Ensino Fundamental, do Distrito Federal, com no mínimo um ano de atuação na área.

Fundamentou-se em referenciais bibliográficos como Aguiar e Duarte (2005), Gorgatti (2008), Brasil (1996), UNESCO (1994), Darido (2008), entre outros.

O objetivo e os procedimentos da pesquisa foram informados aos voluntários, por meio do Termo de Consentimento Livre e Esclarecido (TCLE), que foi assinado e devidamente devolvido para validar a participação no estudo.

A pesquisa para fundamentação do trabalho de conclusão de curso foi submetida ao Comitê de Ética em Pesquisa do Centro Universitário de Brasília - UniCEUB e aprovado com CAAE 54971116.5.0000.0023.

Para a coleta dos dados, foi utilizado um questionário com dez questões fechadas e abertas, visando avaliar as experiências e expectativas do professor, quanto à importância da Educação Física como forma inclusiva. 
Para análise estatística dos resultados obtidos, foi utilizado o programa Word e o programa Excel 2010.

\section{Resultados}

Este estudo teve como objetivo verificar, por meio da percepção dos professores, de que forma as aulas de Educação Física promovem a inclusão dos alunos que apresentam necessidades educacionais especiais. A coleta se deu por meio de um questionário com dez questões, fechadas e abertas.

O primeiro item teve o intuito de verificar o tempo na área de atuação dos professores, observando-se que $30 \%$ dos participantes já atuam na área de educação entre 3 a 8 anos, 30\% atuam entre 10 e 19 anos e 40\% relataram que atuam na área entre 20 e 27 anos, conforme descrito na figura 1 .

Figura 1- Tempo de exercício na área da Educação Física.

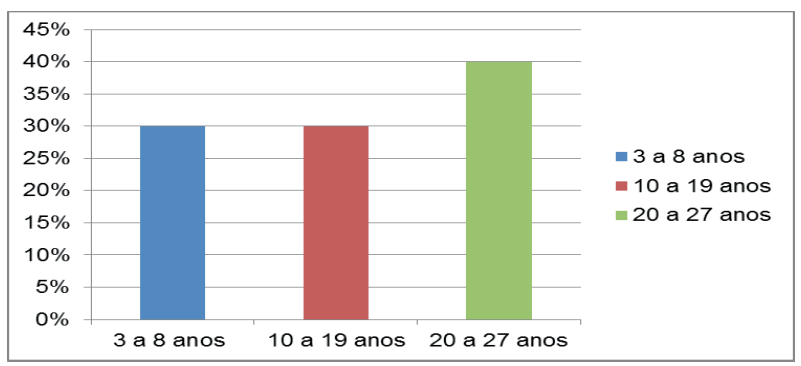

Fonte: Dos autores

Sobre o grau de formação de cada voluntário, foi possível observar que $20 \%$ possuem, apenas, a graduação, 70\% apresentam pós-graduação e, somente, 10\% têm mestrado, de acordo com a figura 2.

Figura 2- Formação acadêmica

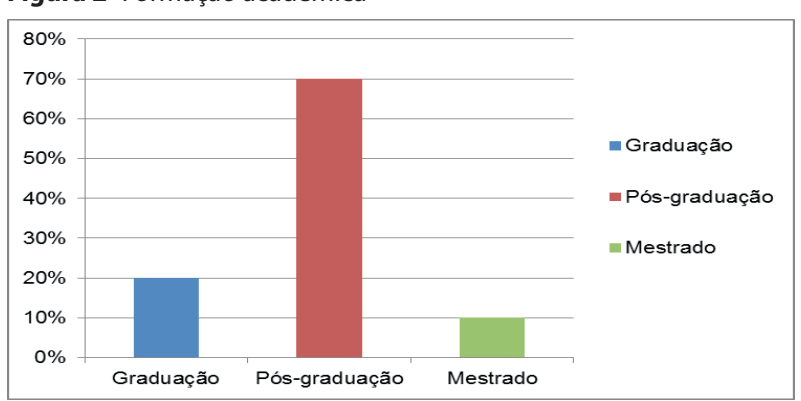

Fonte: Dos autores

Constatamos, também, que $100 \%$ dos professores declararam já trabalharem e continuam trabalhando com alunos com necessidades especiais, o que é um dado significativo para a presente pesquisa.

Quando questionados se dispunham de algum curso ou pós-graduação na área de educação inclusiva, $50 \%$ dos professores relataram que sim e $50 \%$ não possuem nenhuma formação específica, conforme a figura 3.

Figura 3- Possuem curso ou pós-graduação na área de educação inclusiva.

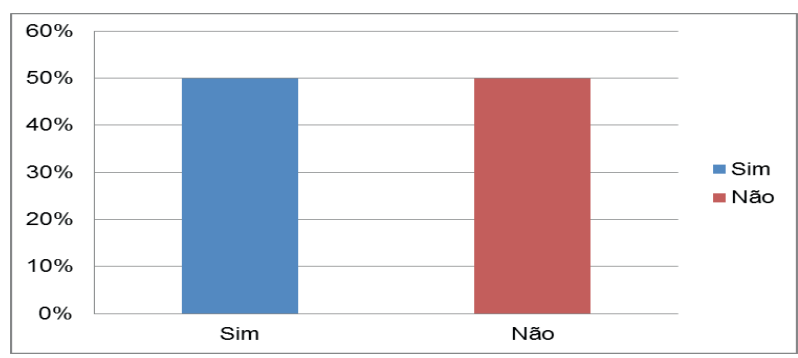

Fonte: Dos autores

Em relação aos cursos de graduação ou alguma pós-graduação na área inclusiva, 60\% dos professores citaram: Jogos lúdicos no ensino especial, educação psicomotora: psicomotricidade relacional, estimulação precoce, autismo e jogos adaptados, em sua formação. Conforme questionário aplicado, todos os professores afirmaram que se consideram aptos a desenvolverem atividades adaptadas aos alunos que apresentam alguma deficiência, demonstrado na tabela $1 .$.

Tabela 1- Relação dos cursos realizados pelos professores na área de educação inclusiva.

\begin{tabular}{lc}
\hline Jogos lúdicos no Ensino Especial & $10 \%$ \\
Estimulação precoce & $10 \%$ \\
Autismo e Jogos adaptados & $10 \%$ \\
Educação Física Inclusiva & $20 \%$ \\
Educação psicomotora: psicomotricidade relacional & $10 \%$ \\
\hline Fonte : Dos autores &
\end{tabular}

Sobre o que eles consideram como processo de inclusão, 50\% responderam ser a inclusão de todos os alunos com necessidades especiais em uma turma regular, de forma gradativa, respeitando a capacidade, habilidades, especificidades e o processo de aprendizagem; $20 \%$ entendem como um processo importante na formação de todos os alunos, que promove o conhecimento, a diversidade e a superação dos próprios limites e 30\% consideram como processo de inclusão a inserção do aluno em todos os processos de aprendizagem, no ambiente de forma adaptada ou natural, independentemente de sua necessidade ou grau de comprometimento, como descrito na tabela 2 . 
Tabela 2- O que os professores entendem como processo de inclusão.

A inclusão de todos os alunos com necessidades especiais em
uma turma regular de forma gradativa respeitando a capacidade, $50 \%$

habilidades, especificidades e o processo de aprendizagem.

Um processo importante na formação de todos os alunos, que promove o conhecimento, a diversidade e a superação dos próprios limites.

Inserir 0 aluno em todos os processos de aprendizagem no ambiente, de forma adaptada ou natural, independente de sua $30 \%$ necessidade ou grau de comprometimento.

Fonte: Dos autores

Indagados sobre como as práticas de Educação Física podem auxiliar no processo inclusivo, 50\% dos participantes acham que a melhor forma é oferecer ao aluno formas de incluir e promover o desenvolvimento intelectual, motor, afetivo e propiciar a socialização e cooperação, enquanto $20 \%$ relataram que esse processo acontece por meio de atividades recreativas, psicomotoras, convivência em grupo, experimentação do corpo em diversas atividades, jogos e brincadeiras, desenvolvendo habilidades básicas, favorecendo autoconfiança e autodomínio e outros $20 \%$ acreditam que promove maior interação, respeito, perspectiva, autoestima, melhorando a identidade do aluno, enquanto $10 \%$ respondeu que esse processo se dá por meio de jogos lúdicos, conforme tabela 3 .

Tabela 3- Como as práticas de educação física podem auxiliar no processo inclusivo.

Oferecendo ao estudante (PNEE) formas de incluir e promover 0 desenvolvimento intelectual, motor, afetivo e propiciando a socialização e cooperação.

Por meio de atividades recreativas, psicomotoras, convivência em grupo, experimentação do corpo em diversas atividades, jogos e brincadeiras, desenvolvendo habilidades básicas, favorecendo autoconfiança e autodomínio.

Promovendo maior interação, respeito, perspectiva, autoestima, melhorando a identidade do aluno.

Realizando-as de forma lúdica

$10 \%$ planejando as aulas para que todos participem, contribuindo de maneira significativa para o desenvolvimento dos alunos e $10 \%$ afirmam que essas atividades adaptadas podem ser desenvolvidas por meio de vivências motoras.

Sobre as dificuldades encontradas pelos professores durante as aulas de Educação Física, 20\% afirmam que faltam materiais, monitores para acompanhar os alunos no decorrer das aulas e falta de espaço físico; $30 \%$ acha que faltam monitores e consideram as turmas muito cheias; $20 \%$ reclamam da falta de estrutura, infraestrutura e monitores, $30 \%$ relatam sobre a resistência por parte da turma, aceitação e realização, adequações de determinadas atividades de forma que todos participem coletivamente, como evidenciado na tabela 4 .

Tabela 4- Dificuldades encontradas pelos professores.

\begin{tabular}{l}
$\begin{array}{l}\text { Falta de material, monitores para o acompanhamento de todos os } \\
\text { alunos e falta de espaço físico. }\end{array}$ \\
$\begin{array}{l}\text { Falta de monitores e turmas com grande quantidade de alunos. } \\
\text { Falta de estrutura, infraestrutura e monitores. }\end{array}$ \\
$\begin{array}{l}\text { Resistência por parte da turma, aceitação e realização, adequações } \\
\text { de determinadas atividades de forma que todos participem } \\
\text { coletivamente. }\end{array}$ \\
\hline $\begin{array}{l}\text { Fonte: Dos autores } \\
20 \%\end{array}$ \\
\hline
\end{tabular}

Ao serem questionados sobre que medidas poderiam ser tomadas a fim de reverter as dificuldades citadas pelos professores, $50 \%$ acham que poderiam haver melhorias com materiais adequados, monitores, cursos de capacitação na área e diagnóstico dos alunos (maioria não possui), aumento de hora/aula por semana e aulas de educação física desde os anos iniciais, 10\% apontam infraestrutura e material adequado; $20 \%$ citam a redução de alunos, $10 \%$ acham que a educação deve vir de casa e $10 \%$ não responderam, como descrito na tabela 5 .

Tabela 5- Que medidas poderiam reverter essas dificuldades.

Materiais adequados, monitores, cursos de capacitação na área e diagnósticos dos alunos (maioria não possui).

Aumento de hora/aula por semana e aulas de educação física desde as séries iniciais.

Infraestrutura e material propício.

Redução de alunos por turma.

Educação familiar que deve ser reforçada na escola, não conduzida. trabalho de inclusão com interesse e comprometimento, 
A respeito de como a Educação Física pode promover a inclusão dos alunos com necessidades especiais e dos demais alunos, $20 \%$ responderam que essa promoção se dá por meio de exercícios em que todos participem, desenvolvendo uma prática educacional mais específica, em que todos aprendam juntos, garantindo um bom nível de ensino aos alunos; $30 \%$ acreditam que a prática promove a inserção e participação de forma lúdica e divertida, de maneira adequada, a cada aluno; $40 \%$ que promove o desenvolvimento intelectual, motor e afetivo, de acordo com suas respostas na questão $06.10 \%$ não opinaram, conforme tabela 6 .

Tabela 6- De qual forma a Educação Física pode promover a inclusão.

$\begin{aligned} & \text { Por meio de exercícios que todos possam participar, desenvolvendo uma } \\
& \text { prática educacional mais específica em que todos aprendam juntos, } \\
& \text { garantindo um bom nível de ensino aos alunos. }\end{aligned}$
$\begin{aligned} & \text { Promovendo a inserção e participação de forma lúdica e divertida de } \\
& \text { maneira adequada a cada aluno. }\end{aligned}$
$\begin{aligned} & \text { Uma forma de educar fisicamente, promovendo a socialização, } \\
& \text { aceitação, cooperação e o desenvolvimento intelectual, motor, afetivo. }\end{aligned}$
\begin{tabular}{l} 
Não respondeu. \\
\hline
\end{tabular}

Fonte: Dos autores

\section{Discussão}

Para Aguiar e Duarte (2005), a inserção do deficiente no espaço e na vida escolar pressupõe alterações no interior e nos procedimentos de ensino e aprendizagem. Nessa vertente, verifica-se que muitos professores estão tentando adequar-se à realidade desses alunos, buscando uma formação apropriada para lidar e melhor atender às necessidades educativas e inclusivas dos alunos com necessidades educacionais especiais.

De acordo com Correa (2001), a inclusão é um grande desafio. Segundo a presente pesquisa, 50\% dos professores relataram que sim e $50 \%$ não possuem nenhuma formação específica na área, o que intensifica esse desafio, pois a formação dos docentes para lidarem com esses alunos é de suma importância.

De acordo com o artigo de Lima e Brito (2012), 97\% dos professores acreditam que a participação do aluno que apresenta deficiências em aulas de Educação Física pode auxiliar na sua inclusão na comunidade escolar. Em contrapartida, na presente pesquisa, 100\% dos professores declaram que trabalham ou continuam tra- balhando com alunos de forma inclusiva, o que é uma forma de reafirmar que essa necessidade de adequação e de respeito está cada vez mais latente nos espaços e contextos escolares e também na prática de educação física.

No entanto, apenas $20 \%$ possuem graduação nessa área, 70\% apresentam pós-graduação e somente 10\% têm mestrado, o que indica que o professor, como mediador e interventor, deve estar comprometido com sua formação continuada e processo de especialização, pois não basta só alterar e modificar o espaço escolar, mas é preciso dar ênfase à formação dos docentes. Está previsto na lei 9.394/96 (LDBEN), em seu artigo 59, inciso III, que os profissionais da educação regular devem buscar a formação continuada para a integração desses alunos nas classes comuns.

Além disso, 40\% dos professores afirmaram que procuram estar atualizados acerca do assunto, mas ainda têm muito a aprender. Dentre eles $40 \%$ realizam o trabalho de inclusão, planejando as aulas para que todos participem, contribuindo de maneira significativa para o desenvolvimento dos alunos. Como método inclusivo de forma prática, $60 \%$ dos professores citaram Jogos lúdicos no ensino especial, Educação psicomotora: psicomotricidade relacional, Estimulação precoce, Autismo e jogos adaptados, entre outros, em sua formação. De acordo com Silva (2005) e Ferreira (2014), os movimentos corporais denotam um fim em si mesmos, mas por meio deles a criança conhece o seu corpo e desenvolve ao máximo suas capacidades motoras e psicossociais.

Os dados obtidos demonstram que há um crescente índice nessa atuação de trabalho, pois 30\% dos participantes já atuam na área de educação física inclusiva entre 3 a 8 anos, 30\% atuam entre 10 e 19 anos e $40 \%$ atuam na área, entre 20 e 27 anos. Segundo Cidade e Freitas (2002) a inclusão é uma atividade que requer transformações em todas as dimensões no ambiente físico e na mentalidade de todas as pessoas, com o intento de se alcançar uma sociedade que respeite e valorize a questão da diversidade humana. A inclusão é, portanto, tema atual, que incide em mudanças culturais e socioculturais.

Para Sassaki (1997) a educação inclusiva, no setor educacional, remete ao conceito de o que viria a ser o processo inclusivo e nesse processo a sociedade se adéqua para conseguir incluir. Afirma que a inclusão deve ser de forma ampla e social, visando reduzir os problemas e equiparar as condições para todos. De acordo com os dados levantados, $50 \%$ dos professores afirmam que a inclu- 
são acontece em uma turma regular, de forma gradativa, respeitando as especificidades e o processo de aprendizagem, promovendo o conhecimento, a diversidade e a superação dos próprios limites.

Segundo Silva e Ferreira (2001), o desenvolvimento motor faz parte do amadurecimento psicomotor interferindo no conhecimento do corpo e no desenvolvimento em níveis cognitivos mais elevados. Para que esse trabalho fosse realizado e inserido no ambiente escolar comum, seriam necessárias adaptações e aparelhagem que dessem suporte aos educandos. Nessa vertente, 50\% dos professores acham que poderia haver melhorias com materiais adequados, monitores, cursos de capacitação na área e diagnósticos dos alunos, ampliação na carga horária e aulas de educação física desde os anos iniciais.

Dessa forma, interpela-se que o sistema educacional como está deveria ser proposto e planejado de uma forma mais eficaz e diversa, pois existem inúmeras dificuldades encontradas pelos professores nas aulas de Educação Física. 20\% afirmam que faltam materiais, monitores para acompanhar os alunos e problemas no espaço físico, 30\% relatam resistência por parte da turma e que essa falta de adequações impossibilita que a inclusão se efetive de uma forma mais ampla.

A respeito de como a Educação Física pode promover a inclusão dos alunos com necessidades especiais e dos demais alunos, $20 \%$ responderam que essa promoção se dá por meio de exercícios em que todos participem, desenvolvendo uma prática educacional mais específica em que todos aprendam juntos, garantindo um bom nível de ensino aos alunos, 30\% acham que a prática promove a inserção e participação de forma lúdica e divertida de maneira adequada a cada aluno.

Para Lapierre (1998) todas as práticas motoras e de atividades físicas e inclusivas fazem parte de um processo de "reeducação," aprimorando e desenvolvendo as potencialidades próprias de cada aluno, ou seja, vale salientar que os processos físicos estão atrelados aos processos cognitivos. E ainda, para os alunos que apresentam deficiências, essas práticas beneficiam os aspectos sociais, de segurança e confiança diante de si mesmo e do mundo a sua volta.

\section{Considerações Finais}

Conclui-se, por meio dos dados coletados na pesquisa e no referencial bibliográfico, que a prática de ativi- dades físicas é de suma importância na inclusão de alunos que apresentam necessidades especiais, em turmas regulares.

No âmbito escolar, a prática de atividades físicas é considerada fundamental para o desenvolvimento cognitivo, afetivo e motor dos alunos, oportunizando também, um ambiente propício para desenvolver a coletividade, cooperação, socialização e o respeito entre eles, independente de qualquer limitação física.

O estudo salienta que a cada dia a inclusão ganha mais espaço e as escolas devem proporcionar um ambiente mais adequado para atender aos alunos com necessidades especiais, e isto inclui recursos materiais, estrutura física, bem como oportunizar a capacitação do professor como um importante mediador do conhecimento, para o desenvolvimento cognitivo, afetivo, social e motor desses alunos.

Ressaltamos a relevância de se conscientizar os professores de Educação Física, para que se faça uma reflexão sobre o desenvolvimento e adaptações de suas aulas, observando sua importância para o processo de inclusão dos alunos que apresentam necessidades educacionais especiais, estimulando sua integração no contexto escolar e na vida.

\section{Referências}

AGUIAR, J. S.; DUARTE, E. Educação Inclusiva: um estudo na área de educação física. Revista Brasileira de Educação Especial, Marília, v. 11, n. 02, p. 233-240, maio/ ago. 2005. doi: 10.1590/S1413-65382005000200005.

ARAUJO, A. N. A Inclusão da Educação Física Escolar: Uma visão Inclusiva. Disponível em: <http://www.webartigos.com/artigos/a-inclusao-da-educacao-fisica-escolar-uma-visao-inclusiva/74929/>. Acesso em: 12 abr. 2015.

BRASIL. Lei de Diretrizes e Bases da Educação Nacional: no 9394/96. Brasília, 1996. Disponível em: <http:// www.planalto.gov.br/ccivil_03/leis/L9394.htm>. Acesso em: 05 abr. 2017.

BRASIL. Ministério da Educação. Parâmetros Curriculares Nacionais: Educação Física. Brasília: MEC/SEF, 1998.

BRITO, R. F. A.; LIMA, J. F. Educação física adaptada e inclusão: desafios encontrados pelos professores de educação física no trabalho com alunos com deficiência. Corpo, Movimento e Saúde, Salvador, v. 2, n. 1, p. 1-12, jan./jun., 2012. 
CARDOSO, M. S. Aspectos históricos da educação especial: da exclusão à inclusão: uma longa caminhada. In: MOSQUERA, J. M.; STOBAÜS, C. (Org.). Educação especial: em direção à educação inclusiva. Porto Alegre: EDIPUCRS, 2003. p. 15-26.

CIDADE, R. E. A.; FREITAS, P. S. Introdução a educação física e ao desporto para pessoas portadoras de deficiência. Curitiba: UFPR, 2002.

SILVA, D. V. da. Contribuições do campo psicomotor para os processos de inclusão na educação. In: CONGRESSO NACIONAL DE EDUCAÇÃO - EDUCERE, 9., 2009, Curitiba. Anais... Curitiba: PUC-PR, 2009. p. 10447-1458.

FERREIRA L. E.; CATALDI C. L. Implantação e implementação da Educação Física Inclusiva. Revista Educação Especial, Santa Maria, v. 27, n. 48, 1-12, abr. 2014. doi: 10.5902/1984686X7635

FIORINI, M. L. S.; MANZINI, E. J. Inclusão de alunos com deficiência na aula de educação física: identificando dificuldades, ações e conteúdos para prover a formação do professor. Revista Brasileira de Educação Especial, Marília, v. 20, n. 3, p. 387-404, jul./set. 2014. doi: 10.1590/ S1413-65382014000300006

GOMES, T. S. Educação física como forma de inclusão de pessoas com necessidades educacionais especiais. 2013. 16f. Trabalho de Conclusão de Curso (Graduação). Curso de Educação Física, Centro Universitário de Brasília, Brasília, 2013.
GORGATTI, M. G. Atividades Físicas e esportivas para crianças e adolescentes com deficiência. 2. ed. Porto Alegre: Artmed, 2008.

KRUG, N. A inclusão de pessoas portadoras de necessidades educativas especiais na educação física escolar. Revista Educação Especial, Santa Maria, v. 15, n. 19, p. 15-23, jan./jun. 2002.

MARTINS, C. L. R. Educação Física Inclusiva: Atitudes dos Docentes. Movimento, Porto Alegre, v. 20, n. 2, p. 637-656, abr./jun. 2014.

MAZINI, M. L. F; ZANELLA, A. L. A importância das aulas inclusivas de Educação Física para os portadores de deficiência. EFDeportes Revista Digital, Buenos Aires, v. 14, n. 139, dez. 2009.

MESQUITA, A. P. S.; ARRUDA, A. L. M. M. O papel do professor diante da inclusão escolar. Revista Eletrônica Saberes da Educação, São Roque, v. 5, n. 1, p. 1-29, jan./ dez. 2014.

SASSAKI, R. K. Inclusão: construindo uma sociedade para todos. Rio de Janeiro: WVA, 1999.

SILVA, K. R. X.; SALGADO, S. S. Construindo culturas de inclusão nas aulas de educação física numa perspectiva humanista. Arquivos em Movimento. Rio de Janeiro, v. 1, n. 1, p. 45-53, jan./jun. 2005.

SILVEIRA C. R.; ALMEIDA, J. J. G. Educação Física escolar: o impacto do processo de inclusão. EFDeportes Revista Digital, Buenos Aires, v. 13, n. 119, abr. 2008.

UNESCO. Declaração de Salamanca. Sobre Princípios, Políticas e Práticas na Área das Necessidades Educativas Especiais, Salamanca: UNESCO, 1994. 